\title{
Experiences of living with dystonia
}

Andrew Morgan, Fiona Eccles and Pete Greasley

Division of Health Research, Lancaster University, Lancaster, UK

Address for correspondence: Andrew Morgan, University of Liverpool, School of Psychology, Brownlow Hill, Liverpool, United Kingdom, L69 3GB, UK.

E-Mail: bosjtb@gmail.com

Word Count: 6,012 (excluding references and tables) 


\section{Experiences of living with dystonia}

Abstract

Purpose: Dystonia is a chronic and incurable movement disorder. This qualitative study aimed to enhance understanding of the condition by exploring the experience of living with dystonia.

Method: Interpretative phenomenological analysis was used to analyse data gathered through semi-structured interviews. Eight participants were recruited via a UK based dystonia charity.

Results: Three superordinate themes emerged from the data: (1) Dealing with ignorance and uncertainty: navigating health services with a rare, poorly understood condition; (2) The challenge of social isolation: overcoming barriers to positive social identity; and (3) Fear of psychological explanations: the impact of stigmatised attitudes towards psychological explanations for dystonia symptoms.

Conclusion: Coping with a rare and chronic condition led to participants feeling isolated and stigmatised by health care services and their communities. Participants were able to overcome this challenge to their identities through the use of social support, particularly from other people with dystonia. Recommendations for reducing the stigmatising experiences of people with dystonia can help to ease the process of adjustment to the illness and enable people to pursue meaningful lives and positive identities. Recommendations for research are aimed at increasing knowledge about these processes.

Keywords: dystonia; identity; interpretative phenomenological analysis; rare diseases; social isolation 


\section{Implications for rehabilitation}

- Dystonia has a pervasive, negative impact on the lives of people with the condition.

- The struggle for diagnosis marks the beginning of a period of psychological adjustment, the difficulty of which is compounded by social isolation and stigma.

- Support groups and peer interaction help people to integrate dystonia into their concept of a meaningful life and identity.

- Health professionals should play a pivotal role in assisting patients during the process of adjustment and on-going self-management through sensitive communication and signposting to wider support services. 


\section{Introduction}

The term dystonia refers to a group of heterogeneous, chronic movement disorders characterised by uncontrollable muscle spasms which can lead to contorted posture or repetitive movements. Types of dystonia have typically been categorised according to age of onset, location of symptoms and aetiology $[1,2,3]$. The prevalence of dystonia is difficult to estimate due to problems accurately diagnosing such a heterogeneous disorder. A meta-analysis conducted in 2012 found a rate of 16 per 100,000 people for primary dystonia (table 1), but the authors believe this to be an underestimation [4].

Traditionally the impact of dystonia has been conceptualised in terms of the severity of motor symptoms [5]. Spasms and contortions can cause significant pain and discomfort, reducing people's ability to work and access the community [6]. As such, dystonia also has a significant social impact and represents an economic health burden [7]. Dystonia is difficult to treat and diagnose effectively due to individual variation in symptoms and reactivity to treatment. This means that people with the condition often have to undergo a frustrating process of trial and error, enduring side effects of treatment with no improvement in their symptoms [8]. This has a negative emotional impact on both patients and health professionals [9].

Although most research and clinical intervention is aimed at ameliorating the physical symptoms of dystonia, attention is increasingly being paid to its psychological and social impact [10]. Research has found that people with dystonia have reduced health related quality of life (HRQOL), scoring lower on all domains in comparison to healthy controls [11]. Severity of motor symptoms do not adequately explain the psychological impact of the condition; for example, severity of depressive symptoms is not significantly correlated with severity of motor symptoms [10]. Neither are differences in HRQOL outcomes fully explained by severity of motor symptoms [12]. The experience of chronic 
illness itself can be argued to be inherently linked to psychological distress, representing a critical life event which demands a process of adjustment, the success of which depends on the availability of psychological and social resources [13]. The psychological and social aspects of dystonia require further investigation in order to more fully understand the impact of the disorder [14].

Research which has been conducted into the links between psychosocial variables and HRQOL outcomes has found that depression and anxiety have a negative relationship with HRQOL $[6,15,16]$. Psychosocial variables such as self-esteem and body concept, and cognitive variables such as memory and attention, are also associated with HRQOL $[12,17]$. Although this research has been successful in establishing some fundamental knowledge about the impact of the condition, thus far the majority of recommendations for research and practice are typically generic and make little reference to the specific nature of dystonia $[18,19]$.

Qualitative research methods provide an effective way to develop an understanding of the condition and elucidate the existing quantitative literature [20], but few exist. A phenomenological study of the impact of spasmodic dysphonia on communication-related quality of life found that participants faced significant barriers to social interaction and that this negatively affected their sense of self [21]. Another study explored life changes for patients with primary dystonia after deep brain stimulation [22]. Thematic analysis found that, although participants viewed their treatment positively, surgery sparked a challenging process of adjustment.

This study complements these more specific studies by taking an open and inductive approach to investigating the broad question of how does dystonia impact the lives of people with the condition. It achieved this by using open inclusion criteria to avoid imposing presuppositions which could hamper the discovery of new insights into 
this topic. This study utilized interpretative phenomenological analysis (IPA), as an inductive method such as this is particularly suitable when the knowledge at stake may be outside the perceptual field of researchers [23].

This study aims to increase knowledge about the experience of living with dystonia and in doing so provide insight for professionals working to support people with dystonia, helping them to understand what support might be helpful, and how and when it should be delivered.

\section{Method}

\section{Design}

IPA was chosen as it is an idiographic, in-depth approach capable of capturing the complex interactions of psychological, social and contextual factors inherent in the experience of living with chronic illness [24]. As a hermeneutic method, IPA is well suited for understanding the experience of chronic ill health because diagnosis often inspires a search for meaning and a period of adjustment and reflection [13].

This study used semi-structured interviews to encourage participants to choose the topics which were most personally salient and to describe them in their own words. Ethical approval for this study was received from the Faculty Ethics Committee at the researchers' institution.

\section{Participant recruitment}

Participants were required to have a diagnosis of dystonia, be 18 years old or over and speak English. Participants were recruited via the Dystonia Society, a UK based dystonia charity. Participants needed to be available for approximately one hour and be able to use 
a telephone, computer or meet in person. In the initial recruitment phase 50 information packs were sent to people on the Dystonia Society's mailing list. Two participants replied and were recruited for the study. Contact was made with the remaining participants via advertising on the Society's social media accounts. Twenty people responded to the advert and the first six who met the criteria were chosen to take part. Participants were selected on this basis as this was an open and inductive study and there were no theoretical, non-arbitrary reasons to favour any particular respondents. For example, quantitative studies into HRQOL have suggested that dystonia type might not have a significant predictive relationship with psychosocial outcomes for people with the condition [11] and so this study did not exclude potential participants for this reason. All selected participants completed the study. A total of eight interviews were conducted: this number was considered to represent the optimal balance between facilitating idiographic and between-participant analysis [16]. All participants provided written consent.

Participant characteristics are presented in table 1. Participants were given pseudonyms to protect their anonymity and identifying information in the transcripts was changed.

[table 1 around here]

\section{Data collection}

Semi-structured interviews ranging in length from 46 to 91 minutes were conducted by the first author either in person, via telephone or via online video conferencing. Call recording software was used during telephone calls and video conferencing. A digital tape recorder was used during the face to face interview. Interviews were transcribed verbatim. 
The interview schedule (table 2) was developed according to the recommendations of Smith et al. [16]. The broad aim of the schedule was to facilitate participants giving an authentic, detailed account of their experiences. Questions were kept open to encourage participants to choose topics which were salient to them and proactively shape the content of the interview. Prompts were used as necessary to facilitate reflection [25], although participants were encouraged to lead the conversation [23] and verbal input from the interviewer was kept to a minimum. The length of schedule was chosen to provide enough context for a 60 minute interview whilst allowing participants to answer in full detail.

The face to face interview was conducted in rented office space. The other participants were briefed on the need to be comfortable, able to concentrate and talk freely for approximately an hour. Each participant conducted the video conferencing or telephone call in their own home and when asked to reflect of impact of their environments during debrief, no issues were reported. It was important to allow participants the option of using the telephone or video conferencing because of the levels of physical disability and social barriers which characterise sections of the target population. As such, these arrangements reduced the burden of participation.

[table 2 around here]

\section{Data analysis}

Analysis was informed by Smith et al. [16] and based upon an interpretivist perspective [26]. The first author engaged in a hermeneutic cycle which began with repeated, line by 
line readings of each transcript and the taking of analytic notes. In keeping with an idiographic approach, each transcript was analysed as completely as possible before moving on to the next [27]. After potential themes were identified within each transcript, comparisons between transcripts were conducted.

Transparency and a critical reflective stance were maintained through the keeping of a detailed audit trail [28] and reflective diary [29] at each step of the process. Legitimacy of interpretation during the process was facilitated by having a selection of participants check initial analysis of their data [30], and having co-authors check the audit trail and the legitimacy of themes at each stage of the process.

The first author was a trainee clinical psychologist at the time of the interviews and had experience of working with people with chronic illnesses in a clinical context. The co-authors supervised the research and were experienced in chronic illness research including with people with other movement disorders.

\section{Results}

Three superordinate themes emerged from the data: (1) Dealing with ignorance and uncertainty: navigating health services with a rare, poorly understood condition; (2) The challenge of social isolation: overcoming barriers to positive social identity; and (3) Fear of psychological explanations: the impact of stigmatised attitudes towards psychological explanations for dystonia symptoms.

\section{Dealing with ignorance and uncertainty}

The first superordinate theme related to the experience of having a rare, poorly understood and unpredictable condition. Participants were forced to cope with their own 
and others' ignorance and a subsequent sense of uncertainty about their condition and the future. All participants contributed to this theme.

\section{Struggling to escape the darkness}

Several participants described the experience of searching for a diagnosis as akin to being in the dark. Even in cases where an accurate diagnosis was given relatively quickly, this process was experienced as a "struggle", which for some participants would last for years. The rarity of the condition meant that neither they nor the health professionals involved understood the cause of their distressing experiences. This, combined with the oppositional attitude of some health professionals, left participants feeling isolated:

It was very stressful, very traumatic $(\ldots)^{1}$ when nobody believes you in the medical world, you just sort of think, well I'm on my own here, how, how am I going to resolve this? So, ermm, really it was very difficult seeing some of these [health professionals] ${ }^{2}$. I'm not saying they were all awful people, but I did have a few along the way that, that did make me feel pretty bad. [Jennifer]

The participants who did not receive an early diagnosis experienced a chain of unhelpful referrals, diagnostic testing and treatment. As avenues for referral were exhausted, contact with their General Practitioner (GP) lessened and participants felt obliged to take control of their care. The internet was a powerful mechanism for

\footnotetext{
${ }^{1}(\ldots)$ indicates removed text.

${ }^{2}$ [text in square brackets] indicates additional information.
} 
education, making contact with third party support services and seeking out private treatment:

I'd managed to do a bit of research myself on the computer and found an organization. [I] got the information from them, and then I, you know, I sort of self-diagnosed really, but the local hospital still weren't having it. They refused to believe that blepharospasm was a form of dystonia (...) the consultant wasn't having it, so (...) I had to arrange a private appointment initially. I basically walked into the consultant's room and within five minutes he'd diagnosed me, which was a huge relief. [Hailey]

The experience of empowerment and relief at successfully finding answers was accompanied by feelings of resentment for participants due to a perceived lack of support from the National Health Service (NHS), which provides free treatment, and at having to pay large sums of money for the answers they needed.

\section{Walking on the treadmill of dystonia}

After the struggle to receive a diagnosis was over, participants faced living with an unpredictable, poorly understood movement disorder, treatment of which has variable impact and significant side effects [8]. Participants felt initially optimistic due to the possible range of treatment options and their belief in the expertise of health professionals. Over time, as options were exhausted, this optimism gave way to an acceptance of dystonia as a pervasive and chronic condition:

I felt at first, quite optimistic, that (...) a way of managing it could be found because you know, they'd say “we'll try this drug and we'll try that drug" and as time went on and I 
went from one to another and Botox didn't work, then I think it dawned on me that, you know, hold on, this thing isn't going to be managed. [Matthew]

Multiple participants invoked a treadmill metaphor to describe the experience of receiving trial and error treatment with no significant improvement in their symptoms. This lack of predictability had an emotional impact on participants who were worn down by the cycle of hope and disappointment, and who felt trapped by an inability to plan for the future.

Participants spoke about the emotionally draining nature of dystonia as a "twentyfour-seven" pervasive disorder. Maria described how the temporary respite afforded by treatment dictated the rhythm of her life. She was not alone in worrying about the sustainability of this cycle. Gradual physical decline due to age, unmanaged symptoms and adaptation to treatment left participants facing an uncertain future:

I've had very mixed results from [treatment] as well. I mean, when I first started going I did, once the [treatment] kicks in (...) you get about four weeks where you're quite stable and then obviously it wears off so you're back to, sort of, square one again, so I did feel like I was living in a constant two monthly cycle. (...) Obviously I'm getting older and I've had the injections for over seven years now (...) They don't seem to be working anymore. [Maria]

Acceptance and working for a positive future

Coping with a lack of hope for improvement and a sense of gradual decline posed a challenge for participants. Those with the most positive outlook on the future focused on 
taking responsibility for their interpretation of experiences in light of a lack of control over their health. Participants emphasised the importance of living day by day:

It's an acceptance, I've got it, err, you know, unless there's some sort of (...) silver bullet, that's going to magically appear, it's sort of, acceptance that I've got this for the rest of my life, so let's make the best of it, let's make the best of everyday. [Jacob]

Some participants sought to replace meaningful aspects of their lives that had been lost, such as work, by committing to new goals. Hailey saw the limitations of dystonia as a "challenge" to be overcome and in committing to doing so, developed a positive, efficacious aspect of her identity:

I probably wouldn't have done quite as much as, as I have (...) I think my character has changed really because I do, I do see various things in life as a bit of a challenge. I think before, ermm, I was, you know, getting on with my job (...) Part of me thinks, “well I have to do it now because I don't know what my eyes will be like in five years' time" (...) At the back of my mind, you have to go out, you have to go and do it now, none of us know what's round the corner anyway do we? (...) I do take life more head on really than I ever did. [Hailey]

\section{The challenge of social isolation}

The second superordinate theme related to the experience of social isolation as a consequence of having dystonia and associated visible differences. Participants felt excluded from their communities and the emotional impact was manifold. This was an experience shared across all participants. 


\section{Isolation as a threat to identity}

Participants mourned identities lost as a result of their disability, which resulted in increased feelings of isolation. Ethan was still in touch with his former colleagues through social media but he spoke with a real despondency and sense of loss about his inability to take part in the activities which to him were a crucial part of group membership:

I used to go to the golf outings with the boys, the taxi boys, that's all had to stop. I cannot do any of that now (...) Aye, I loved it (...) I don't do any of the things anymore, it's too much for me (...) I hate it, I would rather go out to the pub on a Sunday and watch the football with the boys (...) or going on the golf outings. That's the parts I really, really miss. [Ethan]

The lack of understanding and acknowledgment from friends led some participants to intentionally divide their social circles and focus on people with whom they were closer. In doing so they sacrificed part of their identity. For Anna this was her sense of self as a fun, spontaneous, party-goer. She was typical in experiencing a sense of guilt for engaging in this self-protective behaviour. This guilt was balanced by feelings of alienation and bitterness towards friends who did not make an effort to accommodate her or acknowledge her negative experiences:

I find it very hard to swallow because they're like, “well why aren't you coming out? Why aren't you drinking?" And then it was kind of a case of, I realised it was easier to shrink my friendship group and have people who cared, who understood [that] I could leave myself with maybe four weeks of being in agony because I pushed myself to go to something that I really shouldn't have done and I just, it was easier to, it sounds awful, but just cut people like that out who just didn't understand. [Anna] 


\section{Visible difference impacting social experiences}

Participants described having a constant, tiring awareness of difference due to their visible contortions and tremors. The negative responses of strangers were experienced by participants as judgmental and were damaging to their self-esteem, making them feel socially isolated. Ethan was typical of participants in coping with the experience of negative evaluation by isolating himself from others, compounding the barriers to social interaction resulting from pain, fatigue and functional disability:

It was just a living nightmare (...) it just basically stopped my life in track and ermm, just basically made me a prisoner in my own home. I didn't like going out because people were staring, ermm, it affected my balance, it knocked my balance off so people were assuming you were either drunk or drugged up because you were staggering. Ermm, I became basically a recluse, I wouldn't leave the house, I hated going out. [Ethan]

\section{Changing social identity in response to isolation}

The barriers to social engagement presented by dystonia forced participants to challenge themselves in order to find new groups and identities which could satisfy their need for emotional and practical support. Support groups, either online or in person, allowed participants to make contact with other people with dystonia. This provided an avenue for sharing experiences and receiving validation, which in turn reduced feelings of isolation. Engagement with support groups also gave participants the opportunity to support others with the condition, which they found added a meaningful aspect to their lives. 
Meeting people with similar experiences allowed participants to let go of the psychological tension resulting from fear of judgement. They described moving experiences of mutual recognition and shared compassionate understanding:

One of the ladies that I [volunteer] with, she's got a benign tremor (...) so I've really connected with her (...) It feels quite, err, a relief to be honest, because I don't need to say too much to her. I see what she's going through (...) It just feels more relaxed, more (...) it's just like a kindred spirit I suppose. She, she's got the same thing as me and we, I just, yeah, I just feel compassionate towards her and she does to me I suppose. [Maria]

For some, learning to accept support was a challenge to their independence and identity. For others, trying to access support was a difficult task which required them to adjust identity in a different way. Several participants described a process of "hardening" in the face of rejection or criticism, particularly from health professionals. Jennifer spoke about feeling forced to become more demanding and aggressive with a mixed sense of sadness and pride:

To be told by consultants, "pull yourself together, don't be so stupid", be sworn at in consulting rooms and everything, I don't have to put up with that, that's just not right. So, ermm, I, I've had to learn to stand my ground a bit shall we say, with, with how I've been treated over the course of time with these people. So, it's made me a stronger person I think, definitely. [Jennifer]

\section{Fear of psychological explanations}

The third superordinate theme related to participants' perception that psychological explanations for their symptoms were stigmatising. This theme was articulated by six of the eight participants. 
It was common for participants to express their relief at receiving a physical explanation for their symptoms. There was a collective sense that psychological factors are "all in your head", with connotations that they are untreatable, unworthy of medical resources and indicative of personal weakness. The discrepancy between the intensity of their experiences and the message that there was not anything "really" wrong with them made participants such as Jennifer feel alienated and angry. For her, receiving a physical label after a long struggle meant validation and recognition of her experiences:

To actually finally have a doctor or a professor actually say to me, "this is a proper condition", ermm, was a massive relief (...) Just, knowing that I had a condition so that if anybody else asked me I can say, "right ok, I've got this, it is a real condition, it's not all in my head, I'm not making it up", ermm, was a massive relief. So, ermm, I was so grateful to that guy for, for sort of telling me that yes, I have got a condition. I'm not, not, just making it up. [Jennifer]

Some health professionals' attitudes towards a rare condition which they could not diagnose and treat as being the fault of patients led participants to internalise doubt and blame:

The way [the physiotherapist] spoke to me was really, really hard because she was like, "but you're just doing this, you're making this happen, you're not trying", but I would (...) do everything they told me to every day (...) That's when I thought, "hang on I can't have somebody just telling me this and it's all in my head and you're making this happen” (...) and I thought, “oh god am I going crazy?” (...) I didn't ever have to see her again, but it was just, it was horrible being treated like that. [Anna] 
The negative connotations of psychological explanations caused some participants to feel embarrassed and ashamed. Sheryl described how she lived in fear of having to tell people that her struggles were "her fault". Her greatest moment of relief was the first time that she heard from a health professional that there was a physical explanation for her symptoms, even though they did not know what it was or how to treat it:

[The doctor] said (...) “As far as I can see, and we're all agreeing, including the professor, that it's definitely physical, you do know that don't you?" I was almost in tears and she said, "what's the matter?", and I said, "well, in the end I was absolutely convinced it was psychological and I'd been so worried thinking, how am I going to tell everyone that it's all in my head? I'd be so mortified." [Sheryl]

Stigmatised attitudes towards psychological explanations contributed to participants' unwillingness to engage with psychological services when feeling distressed about their situation. Ethan was one of three participants who had previously experienced suicidal ideation and he was typical of participants in preferring to speak informally to trusted people about his distress, rather than accepting a referral to mental health services:

I would rather just [talk to my GP], I've always kind of just done it that, that way. I think it's cos I know him it's good to get it out in the open to him. I would feel quite, I don't know, ermm, nervous, apprehensive about, with a stranger. [Ethan]

\section{Discussion}

The most salient experiences for participants of this study were those relating to isolation and its impact on their sense of self. This is consistent with the evidence that positive 
group membership and social identity have a significant impact on wellbeing and quality of life, operating as part of a positive feedback cycle between perceptions of the self and others [31]. Equally, stigmatised identities and group memberships have been found to produce negative feedback and reduce wellbeing [32]. With regards to stigma, people with dystonia are in a particularly vulnerable position. The disorder represents an intersection of rare, visible, chronic and often unexplained illness, all of which have associated stigma $[33,34,35]$. In order to increase social connectedness and wellbeing for people with dystonia, it is important to understand and mitigate experiences of stigma and isolation.

\section{Navigating health services with a rare condition}

Participants reacted with anger at the struggle they faced for a diagnosis and the antagonistic relationship that developed with health professionals. Rare or unexplained conditions can represent a challenge to traditional patient-doctor relationships and cause conflict, demanding that both parties adjust their role perceptions in order to achieve progress [34]. Typically doctors are less likely to have knowledge of the specific condition and patients are obliged to assume more control, as was the case for participants in this study. Stigmatisation of patients seen to be upsetting established processes and balance of roles can lead to GPs providing a less person-centred service, shorter consultations and operating with impaired clinical judgment [34, 35].

Although the internet was seen as a source of knowledge and empowerment, participants also felt exposed to misinformation and exploitation and were consistent with other groups in expressing a preference for health professionals taking control of their care [36]. In order to facilitate self-management for people with rare and undiagnosed 
conditions, GPs could receive training aimed at developing a facilitator role, wherein they explain and contextualise information for patients, rather than competing with them for authority [36, 37, 38].

It is unrealistic to expect GPs to be able to consistently and accurately identify rare diseases. Grounded theory research into the relationship between GPs and consultants has found that both parties lack the time to confer due to excessive workload and desynchronised workflow [39]. The subsequent lack of information sharing and its impact on holistic care was an issue highlighted by participants of this study. Sampson et al. [39] recommend a protected time for information sharing between GPs and specialists. Helping GPs to more effectively manage the care of people with rare or undiagnosed conditions may reduce the associated emotional burden and improve the experience of patients.

\section{Finding social support}

Participants described experiencing stigmatising reactions to their ambiguous, visible symptoms. These reactions caused feelings of shame and participants subsequently limited their interaction with their communities. This experience echoes the findings of stroke survivors and people with Parkinson's disease [40, 41]. This self-imposed social isolation can have a snowball effect whereby people begin to feel depressed and further self-isolate [42].

Chronic illness was experienced as a biographical disruption which threatened the identity of participants [43]. The identity restoration hypothesis posits that people with threatened identities will often feel compelled to develop or repair their social identity [31] particularly salient for people who are members of a group which they cannot leave,

for example those with incurable illnesses [44]. The experience of participants and related 
research suggests that support groups are one of the most effective ways to facilitate this restoration $[31,45,46]$. Support groups can promote positive social comparisons and cultivate a sense that overcoming the challenges of ill health makes the person more virtuous than before. This process of creative redefinition [47] can form part of a positive feedback cycle wherein positive conceptions of one's peers enhance personal identity [31]. Furthermore, peer interaction provides perspective and information for people who are otherwise isolated in their experiences [48, 49]. Group meetings also offer a supportive venue for expressing negative emotions, which helps people feel acknowledged and validated [46, 50], as well as an opportunity to help others [51].

Members of support groups are more likely than non-members to have accepted their condition and incorporated it into a positive identity [31, 52] and initial engagement with face to face support groups can provoke anxiety [45]. These barriers mean that, as with three participants in this study, some people prefer one to one peer interaction or online support groups. Online support groups can tend towards a biomedical emphasis and the sharing of technical information, rather than emotional support [53]. As such, they represent an alternative for people who want specific, pragmatic, experiential knowledge from their peers but for whom face to face groups are unsuitable [54].

Participants in this study complained about health professionals' lack of awareness of support groups, which they felt was indicative of a lack of holistic support in general. Bodenheimer et al. [55] claimed that connecting patients with chronic illness to community resources should be a priority for acute-focused care services, given the inability of these services to deal with the long term needs of patients. 


\section{Dealing with self-doubt and alienation}

Participants were almost unanimous in their perception of psychological explanations for their symptoms as dismissive and stigmatising. Health professionals' negative attitudes towards psychological explanations were perceived as reinforcing stigmatised views of participants. Although all participants reported significant psychological distress, with two attempting suicide, none had received specific, psychological support before or after their diagnosis. Some participants expressed negative attitudes towards utilising mental health services and were wary of being further stigmatised by health professionals. It is possible that their negative experiences during the struggle for diagnosis contributed to these attitudes.

That health professionals often have a stigmatised attitude towards psychological explanations is well established in the literature. A review of nurses' attitudes echoed the experience of participants, finding that respondents believed psychological symptoms were attributable to personal weakness, laziness and lack of self-control [56]. This pattern is present across different types of health professionals, including medical specialists [57]. Participants' own stigmatised views of psychological distress and mental health also represented a barrier to engagement. Psychoeducation offered pre-emptively can help reduce stigma and it may be that GPs could signpost to information [58].

If barriers to engagement were reduced to the extent that patients felt able to engage in psychological intervention, this could assist with a range of issues raised in this study such as the process of psychological adjustment and decision making about treatment [59]. Acceptance and Commitment Therapy (ACT) represents a potentially effective model, which in the context of chronic ill health, aims to facilitate the process of acceptance of illness and commitment to meaningful action intended to enhance wellbeing [60]. A review of ACT for chronic illness concluded that the evidence base is 
currently small and of low quality, but that there are suggestions that the approach could potentially be useful for this population [61]. A review of behavioural interventions for adult onset primary dystonia [62] similarly concluded that more quality research is needed, but that there is reason to believe that behavioural interventions could assist selfmanagement of dystonia outside clinical settings. An example of such a programme was piloted by Sandhu et al. [63], who concluded that a combined cognitive behavioural and mindfulness programme could assist self-management and an integrated approach to managing the psychosocial impact of dystonia.

\section{Strengths and limitations}

Despite dystonia being a heterogeneous condition, the sample for this study was sufficiently homogenous for effective IPA analysis as demonstrated by the production of three coherent, robust themes constructed from the accounts of the majority of participants. The consistency of experiences between people with different types of dystonia suggests that the most salient aspects of experience are not related to the particular manifestation of motor symptoms, but the more general psychological and social impact of the condition.

Participants in this study represent a self-selecting sample as they had experiential knowledge of the specific phenomenon of interest, were motivated enough to participate and were in contact with the Dystonia Society. It is possible that participants were motivated to tell their stories because of how adverse their experiences were and that this gives a particularly negative impression of the experience of living with dystonia.

Another aspect of recruitment which bears consideration is that advertising on social media networks requires that potential participants have internet access, be computer literate to some degree and be relatively active on social media. The sampling 
could therefore have excluded a set of people who, for example, were from lower socioeconomic groups or had greater levels of disability. Studies of internet sampling have concluded however that online sampling methods reach a relatively diverse socioeconomic range [64]. This study sought to minimise the impact of disability on accessibility by offering participants the choice of telephone, video conferencing or face to face interviews. This also ensured that it was possible to recruit a sufficient sample. Although telephone interviews lack some information communicated through non-verbal behaviour, comparisons of telephone and face to face interviews found no significant difference in quality of data $[65,66]$.

\section{Further research}

IPA designs with more purposive sampling could be used to further explore the experiences of people with dystonia. It is possible that if people with only one type of dystonia were interviewed that the emergent themes would be different. For example, two of the three participants with cervical dystonia spoke about the challenge of managing pain caused by the condition, including struggling at times with opioid addiction. Other potential factors which could be explored include time since diagnosis or responsiveness to treatment. Recruitment of a sample through a hospital treatment program could include more people for whom treatment was effective, which may have an impact on their relationship to the disorder and their perspective on the future. A study with multiple interviews per participant, beginning shortly after diagnosis, could shed light on the process of adjustment and meaning making. Recording the experiences of participants whilst they are still recent may produce different results than in studies such as this, where participants are often reflecting on experiences which took place years earlier [13]. 
In terms of quantitative research, more high quality studies of the efficacy of ACT and behavioural interventions for people with dystonia and related conditions are needed, particularly in the form of randomised controlled trials with long term follow up assessments [60].

This study has identified a range of psychological processes and potential variables of interest that warrant further attention. Future research should investigate the impact of stigma, availability of social resources and patient-health professional dynamics on the wellbeing of people with dystonia. Although this study was not designed to investigate differences between participants, another issue which demands attention is the effect of pre-morbid personality and attachment on how people are impacted by these factors. Research with other populations suggests it could be an important part of the complexity of this topic $[67,68,69]$.

\section{Conclusion}

Participants in this study described a struggle for explanation, recognition and validation of their experiences. This left participants feeling isolated from health professionals and their community, and alienated from themselves. The mutual exchange of support with peers helped participants to integrate the experience of dystonia with a positive sense of identity. Although people with dystonia represent a particularly vulnerable group in terms of exposure to stigma, the experiences described by participants were typically in keeping with those of people with other, similar health conditions. The recommendations for practice and research could help shorten the process of acceptance and the development of a positive identity for people with dystonia. 


\section{Acknowledgements}

The authors would like to thank the Dystonia Society and all of the participants.

\section{Declaration of interest}

The author reports no conflicts of interest. 


\section{References}

1. Andrews C, Aviles-Olmos I, Hariz M, et al. Which patients with dystonia benefit from deep brain stimulation? A metaregression of individual patient outcomes. J Neurol Neurosurg Psychiatry. 2010;12(81):1383-1424.

2. Fahn S, Calne DB. Classification and investigation of dystonia. In: Marsden CD FS, editor. Movement Disorders 2. London: Butterworths; 1987. p. 332-358.

3. Fahn S. Classification of movement disorders. Mov Disord. 2011;26(6):947-957.

4. Steeves TD, Day L, Dykeman J, et al. The prevalence of primary dystonia: A systematic review and meta-analysis. Mov Disord. 2012;27(14):1789-1796.

5. Albanese A, Sorbo FD, Comella C, et al. Dystonia rating scales: critique and recommendations. Mov Disord. 2013;28(7):874-883.

6. Pekmezovic T, Svetel M, Ivanovic N, et al. Quality of life in patients with focal dystonia. Clin Neurol Neurosurg. 2009;111(2):161-164.

7. Poliziani M, Koch M, Liu X. Striving for more good days: patient perspectives on botulinum toxin for the treatment of cervical dystonia. Patient Prefer Adherence. 2016;10:1601-1608.

8. Kongsaengdao S, Maneeton B, Maneeton N. Quality of life in cervical dystonia after treatment with botulinum toxin A: a 24-week prospective study. Neuropsychiatr Dis Treat. 2017;13:127-132.

9. Lohmann K, Klein C. Genetics of dystonia: what's known? What's new? What's next? Mov Disord. 2013;28(7):899-905. 
10. Stamelou M, Edwards MJ, Hallett M, et al. The non-motor syndrome of primary dystonia: clinical and pathophysiological implications. Brain. 2011;135(6):1668-1681.

11. Page D, Butler A, Jahanshahi M. Quality of life in focal, segmental, and generalized dystonia. Mov Disord. 2007;22(3):341-347.

12. Ben-Shlomo Y, Camfield L, Warner T. What are the determinants of quality of life in people with cervical dystonia? J Neurol Neurosurg Psychiatry. 2002;72(5):608614.

13. Sharpe L, Curran L. Understanding the process of adjustment to illness. Soc Sci Med. 2006;62(5):1153-1166.

14. McNeill A. Aetiology of co-morbid psychiatric disorders in dystonia: a biopsychosocial hypothesis. Internet J Neurol. 2004;2(2).

15. Degirmenci Y, Oyekcin DG, Bakar C, et al. Anxiety and depression in primary and secondary dystonia: a burden on health related quality of life. Neurol Psychiatry Brain Res. 2013;19(2):80-85.

16. Smith JA, Flowers, P, \& Larkin, M. Interpretative phenomenological analysis: Theory, method, and research. Thousand Oaks (CA): SAGE; 2009.

17. Kuyper DJ, Parra V, Aerts S, et al. Nonmotor manifestations of dystonia: a systematic review. Mov Disord. 2011;26(7):1206-1217.

18. Jinnah HA, Berardelli A, Comella C, et al. The focal dystonias: Current views and challenges for future research. Mov Disord. 2013;28(7):926-943.

19. Tan E-K, Lum S-Y, Fook-Chong S, et al. Behind the facial twitch: depressive 
symptoms in hemifacial spasm. Parkinsonism Relat Disord. 2005;11(4):241-245.

20. Hearn JH, Cotter I, Fine P, et al. Living with chronic neuropathic pain after spinal cord injury: an interpretative phenomenological analysis of community experience.

Disabil Rehabil. 2015;37(23):2203-2211.

21. Baylor CR, Yorkston KM, Eadie TL. The consequences of spasmodic dysphonia on communication-related quality of life: A qualitative study of the insider's experiences. J Commun Disord. 2005;38(5):395-419.

22. Hariz GM, Limousin P, Tisch S, et al. Patients' perceptions of life shift after deep brain stimulation for primary dystonia—A qualitative study. Mov Disord. 2011;26(11):2101-2106.

23. Biggerstaff $\mathrm{D}$, Thompson AR. Interpretative phenomenological analysis (IPA): A qualitative methodology of choice in healthcare research. Qual Res Psychol. 2008;5(3):214-224.

24. Brocki JM, Wearden AJ. A critical evaluation of the use of interpretative phenomenological analysis (IPA) in health psychology. Psychol Health. 2006;21(1):87108.

25. Pietkiewicz I, Smith JA. A practical guide to using interpretative phenomenological analysis in qualitative research psychology. Psychol J. 2014;20(1):7.

26. Gray DE. Doing research in the real world. Thousand Oaks (CA): SAGE; 2013.

27. Pringle J, Drummond J, Hendry C, et al. Interpretative phenomenological analysis: a discussion and critique. Nurse Res. 2011;18(3):20-24. 
28. Whitehead L. Enhancing the quality of hermeneutic research: Decision trail. J Adv Nurs. 2004;45(5):512-518.

29. Vicary S, Young A, Hicks S. A reflective journal as learning process and contribution to quality and validity in interpretative phenomenological analysis. Qual Soc Work. 2017;16(4):550-565.

30. Lincoln YS, Guba EG. Naturalistic inquiry. Thousand Oaks (CA): SAGE; 1985.

31. Jetten J, Haslam SA, Cruwys T, et al. Advancing the social identity approach to health and well-being: Progressing the social cure research agenda. Eur J Soc Psychol. 2017;47(7):789-802.

32. Kellezi B, Reicher S. Social cure or social curse? The psychological impact of extreme events during the Kosovo conflict. In: Jetten J, Haslam C, Haslam A, editors. The social cure: identity, health and well-being. London: Psychology Press; 2012. p. 217 233.

33. Maffoni M, Giardini A, Pierobon A, et al. Stigma experienced by Parkinson's disease patients: a descriptive review of qualitative studies. Parkinsons Dis. 2017;2017:17.

34. Wileman L, May C, Chew-Graham CA. Medically unexplained symptoms and the problem of power in the primary care consultation: a qualitative study. Fam Pract. 2002;19(2):178-182.

35. Hart A, Henwood F, Wyatt S. The role of the Internet in patient-practitioner relationships: findings from a qualitative research study. J Med Internet Res. 2004;6(3):e3. 
36. Stevenson FA, Kerr C, Murray E, et al. Information from the Internet and the doctor-patient relationship: the patient perspective-a qualitative study. BMC Fam Pract. 2007;8(1):47-55.

37. Budych K, Helms TM, Schultz C. How do patients with rare diseases experience the medical encounter? Exploring role behavior and its impact on patient-physician interaction. Health policy. 2012;105(2):154-164.

38. McMullan M. Patients using the Internet to obtain health information: how this affects the patient-health professional relationship. Patient Educ Couns. 2006;63(1):2428.

39. Sampson R, Barbour R, Wilson P. The relationship between GPs and hospital consultants and the implications for patient care: a qualitative study. BMC Fam Pract. 2016;17(1):1-12.

40. Bramley N, Eatough V. The experience of living with Parkinson's disease: An interpretative phenomenological analysis case study. Psychol Health. 2005;20(2):223235.

41. Murray CD, Harrison B. The meaning and experience of being a stroke survivor: an interpretative phenomenological analysis. Disabil Rehabil. 2004;26(13):808-816.

42. Simpson J, McMillan H, Reeve D. Reformulating psychological difficulties in people with Parkinson's disease: the potential of a social relational approach to disablism. Parkinsons Dis. 2013;2013.

43. Bury M. Chronic illness as biographical disruption. Sociol Health Illn. 1982;4(2):167-182. 
44. Best D, Beckwith M, Haslam C, et al. Overcoming alcohol and other drug addiction as a process of social identity transition: the social identity model of recovery (SIMOR). Addict Res Theory. 2016;24(2):111-123.

45. Finlay KA, Elander J. Reflecting the transition from pain management services to chronic pain support group attendance: An interpretative phenomenological analysis. Br J Health Psychol. 2016;21(3):660-676.

46. Sheehy TL, McDonough MH, Zauber SE. Social Comparisons, Social Support, and Self-Perceptions in Group Exercise for People With Parkinson's Disease. J Appl Sport Psychol. 2017;29(3):285-303.

47. Branscombe NR, Fernandez S, Gomez A, et al. Moving toward or away from a group identity: Different strategies for coping with pervasive discrimination. In: Jetten J, Haslam C, Haslam A, editors. The social cure: identity, health and well-being. London: Psychology Press; 2012. p. 115-131.

48. Hogan BE, Linden W, Najarian B. Social support interventions: Do they work? Clin Psychol Rev. 2002;22(3):381-440.

49. Repper J, Carter T. A review of the literature on peer support in mental health services. J Ment Health. 2011;20(4):392-411.

50. Davison KP, Pennebaker JW, Dickerson SS. Who talks? The social psychology of illness support groups. Am Psychol. 2000;55(2):205-217.

51. Martin R, Levack WM, Sinnott KA. Life goals and social identity in people with severe acquired brain injury: An interpretative phenomenological analysis. Disabil Rehabil. 2015;37(14):1234-1241. 
52. Charlton GS, Barrow CJ. Coping and self-help group membership in Parkinson's disease: an exploratory qualitative study. Health Soc Care Community. 2002;10(6):472478.

53. Lasker JN, Sogolow ED, Sharim RR. The role of an online community for people with a rare disease: content analysis of messages posted on a primary biliary cirrhosis mailinglist. J Med Internet Res. 2005;7(1).

54. Solomon P. Peer support/peer provided services underlying processes, benefits, and critical ingredients. Psychiatr Rehabil J. 2004;27(4):392-401.

55. Bodenheimer T, Wagner EH, Grumbach K. Improving primary care for patients with chronic illness. Jama. 2002;288(14):1775-1779.

56. Ross CA, Goldner EM. Stigma, negative attitudes and discrimination towards mental illness within the nursing profession: a review of the literature. J Psychiatr Ment Health Nurs. 2009;16(6):558-567.

57. Horsfall J, Cleary M, Hunt GE. Stigma in mental health: Clients and professionals. Issues Ment Health Nurs. 2010;31(7):450-455.

58. Jones A, Crossley D. 'In the mind of another'shame and acute psychiatric inpatient care: an exploratory study. A report on phase one: service users. J Psychiatr Ment Health Nurs. 2008;15(9):749-757.

59. British Psychological Society. Briefing Paper No. 27 Clinical Health Psychologists in the NHS. Leicester (UK): The British Psychological Society; 2008.

60. McCracken LM, Vowles KE. Acceptance and commitment therapy and mindfulness for chronic pain: model, process, and progress. Am Psychol. 2014;69(2):178. 
61. Graham CD, Gouick J, Krahé C, et al. A systematic review of the use of Acceptance and Commitment Therapy (ACT) in chronic disease and long-term conditions. Clin Psychol Rev. 2016;46:46-58.

62. Bernstein CJ, Ellard DR, Davies G, et al. Behavioural interventions for people living with adult-onset primary dystonia: a systematic review. BMC Neurol. 2016;16:40.

63. Sandhu H, Bernstein C, Davies G, et al. Combined cognitive-behavioural and mindfulness programme for people living with dystonia: a proof-of-concept study. BMJ Open. 2016;6(8).

64. Gosling SD, Mason W. Internet research in psychology. Annu Rev Psychol. $2015 ; 66: 887-902$.

65. Sturges JE, Hanrahan KJ. Comparing telephone and face-to-face qualitative interviewing: a research note. Qual Res. 2004;4(1):107-118.

66. Vogl S. Telephone versus face-to-face interviews: Mode effect on semistructured interviews with children. Sociol Methodol. 2013;43(1):133-177.

67. Andrews RM, Browne AL, Drummond PD, et al. The impact of personality and coping on the development of depressive symptoms in adult burns survivors. Burns. 2010;36(1):29-37.

68. Kim S-Y, Kim J-M, Stewart R, et al. Influences of personality traits on quality of life after stroke. Eur Neurol. 2013;69(3):185-192.

69. Sela-Kaufman M, Rassovsky Y, Agranov E, et al. Premorbid personality characteristics and attachment style moderate the effect of injury severity on occupational outcome in traumatic brain injury: another aspect of reserve. J Clin Exp Neuropsychol. 
2013;35(6):584-595. 
Table 1. Participant characteristics.

\begin{tabular}{cccccccc}
\hline Pseudonym & Gender & Age & Age at first & Dystonia type* & Interview type & Ethnicity & Employment status \\
\hline Matthew & Male & 61 & 53 & Oromandibular & Face to face & White British & Retired \\
\hline Hailey & Female & 66 & 43 & Blepharospasm & Telephone & White British & Retired \\
\hline Jennifer & Female & 50 & 35 & Fixed & Telephone & White British \\
\hline Anna & Female & 31 & 23 & Segmental & Video conferencing & White Indo-Caribbean & Employed \\
\hline Sheryl & Female & 55 & 34 & Generalised & Telephone & White British \\
\hline Jacob & Male & 56 & 54 & Cervical & Telephone & White British \\
\hline Maria & Female & 56 & 26 & Cervical & Telephone & White British \\
\hline Ethan & Male & 42 & 36 & Cervical & Telephone & White British
\end{tabular}


*Description of dystonia types:

Primary- Dystonia with no known exogenous cause

Oromandibular- Dystonia of the mouth, tongue or jaw

Blepharospasm- Dystonia of the eyelids

Fixed- Fixed limb postures after peripheral injury

Segmental- Dystonia affecting two contiguous areas of the body

Generalised- Dystonia affecting multiple areas of the body

Cervical- Dystonia of the neck 
Table 2. Interview schedule.

$\underline{\text { Topic area 1: Background and diagnosis }}$

- Can you tell me about when you first experienced symptoms of dystonia?

- Can you tell me about any medical treatment you have received for dystonia?

Topic area 2: The physical impact of symptoms

- What kind of symptoms do you experience?

- What impact, if any, do your symptoms have on your day to day life?

Topic area 3: The psychological impact of symptoms

- Has the experience of having dystonia had any impact on how you feel/your state of mind?

- How do you feel about having dystonia?

Topic area 4: Support and coping

- Is there anything that helps you to manage dystonia? 
- Are there any specific people or groups that help you to manage having dystonia?

\section{$\underline{\text { Topic area 5: General issues }}$}

- Is there anything else that you feel is important to talk about? 